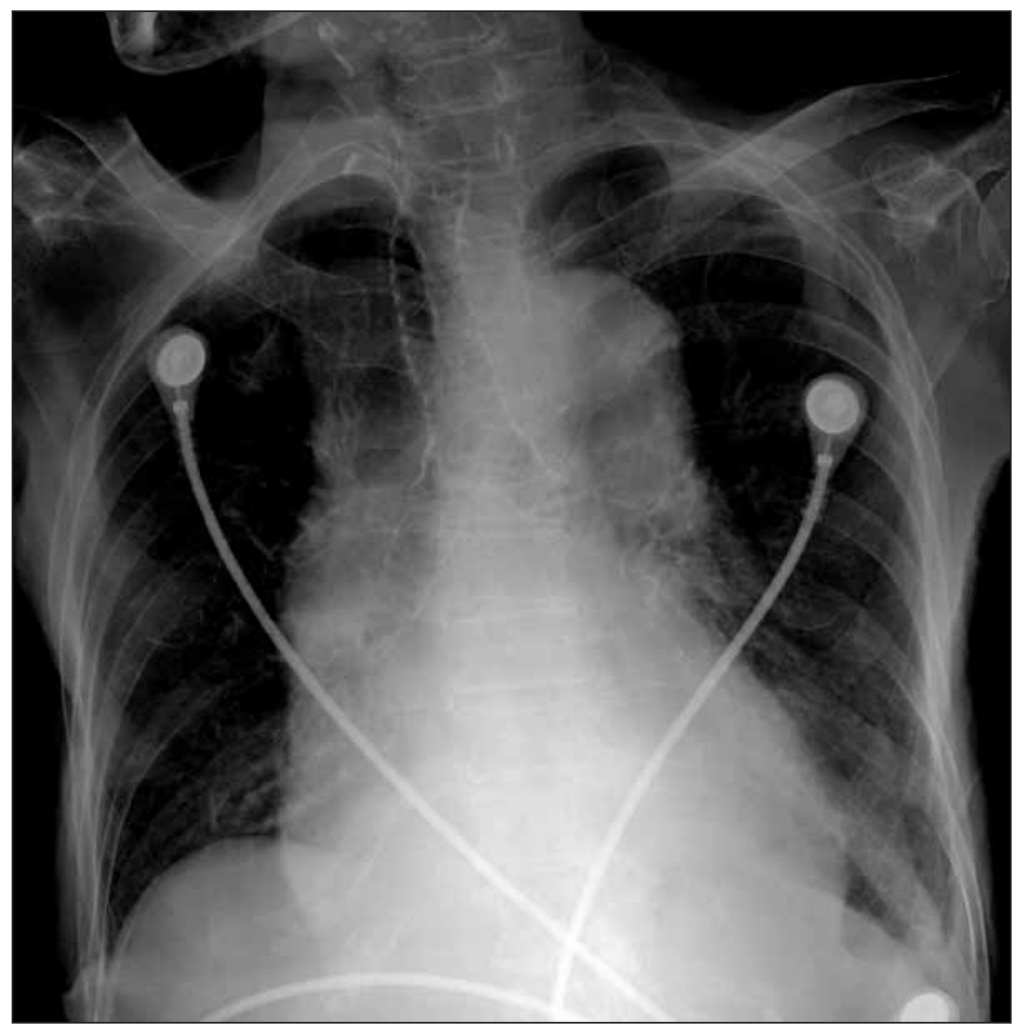

Figure 1: Chest radiograph showing extensive tracheobronchial calcification forming a dear outline of the patient's large and smaller airways, which are usually radiolucent.

\title{
Tracheal calcification
}

\begin{abstract}
A
92-year-old woman was admitted to our hospital because of congestive heart failmarkable, this finding is of no practical clinical significance. However, tracheal calcification may occur more often among patients who have taken an anticoagulation medication, such as warfarin sodium, for several years. ${ }^{1}$ Although the mechanism by which warfarin causes tracheal calcification is unknown, it may inhibit the normal formation of a vitamin $\mathrm{K}$-dependent protein that prevents calcification of cartilage and connective tissue. ${ }^{2}$
\end{abstract}

Clinical images are chosen because they are particularly intriguing, classic or dramatic. Submissions of clear, appropriately labelled high-resolution images must be accompanied by a figure caption and the patient's written consent for publication. A brief explanation (300 words maximum) of the educational significance of the images with minimal references is required.
Sang-Ho Jo MD MMS

Young-Jin Choi MD PhD

Goo-Yeong Cho MD PhD

Hyun-Sook Kim MD PhD Ki-Suck Jung MD PhD

Chong-Yun Rhim MD PhD

Department of Internal Medicine,

Hallym University Sacred Heart

Hospital, Anyang-si, Gyeonggi-Do, Korea

\section{REFERENCES}

1. Taybi H, Capitanio M. Tracheobronchial calcification: an observation in three children after mitral valve replacement and warfarin sodium therapy. Radiology 1990;176:728-30.

2. Price PA, Faus SA, Williamson MK Warfarin causes rapid calcification of the elastic lamellae in rat arteries and heart valves. Arterioscler Thromb Vasc Biol 1998;18:1400-7. 